\title{
Performance Optimization of Centrifugal Pump for Crude Oil Delivery
}

\author{
S.A.I. Bellary ${ }^{a}$, A. Husain ${ }^{*}$, b, A. Samadc and R.A. Kanai ${ }^{\mathrm{a}}$ \\ a Annasaheb Dange College of Engineering and Technology, Ashta, Sangli-416301, India. \\ ${ }^{b}$ Department of Mechanical and Industrial Engineering, Sultan Qaboos University, PO Box 33, Al-Khoudh, PC 123, \\ Muscat, Sultanate of Oman. \\ c Department of Ocean Engineering, Indian Institute of Technology Madras, Chennai-600036, India.
}

\begin{abstract}
Crude oil transport is an essential task in oil and gas industries, where centrifugal pumps are extensively used. The design of a centrifugal pump involves a number of independent parameters which affect the pump performance. Altering some of the parameters within a realistic range improves pump performance and saves a significant amount of energy. The present research investigated the pump characteristics by modifying the number of blades and the exit blade-angles. Reynolds-Averaged Navier-Stokes equations with standard $k-\varepsilon$ two-equation turbulence closure were used for steady and incompressible flow of crude oil through the pump. The experimental set-up was installed and the pump performance calculated numerically was compared with the experiments. The investigations showed that the number of blades and the exit blade-angles have a significant influence on the head, shaft power, and efficiency. The vortical flow structures, recirculation and reverse flow characteristics around the impeller were investigated to explain the flow dynamics of impeller and casing. A larger number of blades on the rotor showed dominant streamlined flow without any wake phenomena. The combined effect of the number of blades and exit blade angle has led to an increase in head and efficiency through the parametric optimization.
\end{abstract}

Keywords: Centrifugal pump; Exit blade-angle; Number of blades; Recirculation; Reverse flow; Vortical Structures; Pump efficiency.

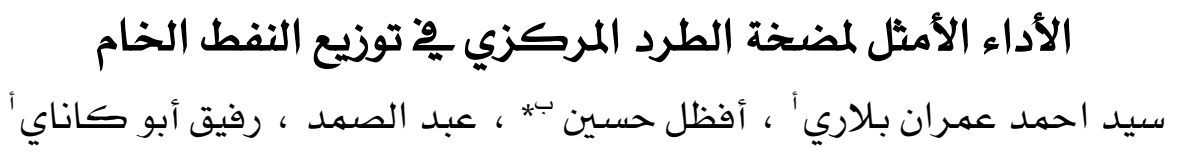

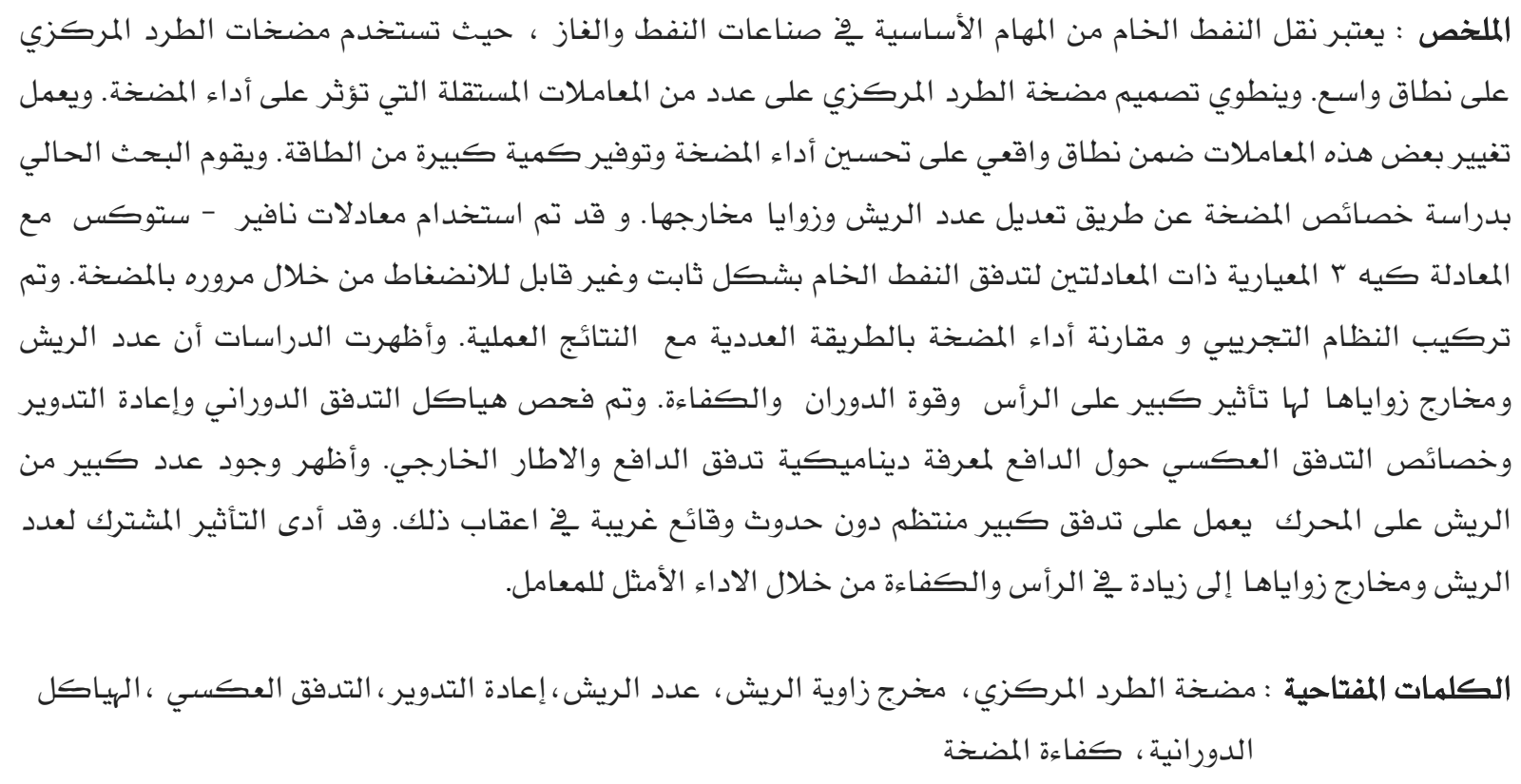

* Corresponding author's e-mail: afzal19@squ.edu.om 


\section{List of Symbols}

$\begin{array}{lll}H & : & \text { Head generated, } \mathrm{m} \\ \Delta H & : & \text { Hydraulic losses, } \mathrm{m} \\ M & : & \text { Power consumed by pump, W } \\ N & : & \text { Impeller speed, } \mathrm{rpm} \\ Q & : & \text { Volume flow rate, } \mathrm{m}^{3} / \mathrm{s} \\ U_{i} & : & \text { Velocity of fluid, } \mathrm{m} / \mathrm{s} \\ \mathrm{Z} & : & \text { Number of blades }\end{array}$

Greek Symbol

$\begin{array}{lll}\beta & : & \text { Exit blade angle } \\ \eta & : & \text { Efficiency, \% } \\ \mu & : & \text { Dynamic viscosity, N.s } / \mathrm{m}^{2} \\ \mu_{t} & : & \text { Turbulent viscosity, N.s } / \mathrm{m}^{2} \\ \rho & : & \text { Density of fluid, } \mathrm{kg} / \mathrm{m}^{3} \\ \sigma & : & \text { Slip factor }\end{array}$

Subscripts

$\begin{array}{lll}\text { act } & : & \text { Actual } \\ \text { h } & : & \text { Hydraulic } \\ \text { in } & : & \text { Input } \\ \text { man } & : & \text { Manometric } \\ \text { mech } & : & \text { Mechanical } \\ \text { motor } & : & \text { Motor } \\ \text { out } & : & \text { Output } \\ \text { theo } & : & \text { Theoretical } \\ \text { ov } & : & \text { Overall } \\ 2 & : & \text { Outlet }\end{array}$

Acronyms

CFD : Computational Fluid Dynamics

RANS : Reynolds-Averaged Navier-Stokes 


\section{Introduction}

Transportation of crude oil is one of the major tasks of the E \& P (exploration and production) companies and centrifugal pumps are extensively used for this application. These pumps transport liquids or mixtures of liquids having a wide range of viscosity and density (Bellary and Samad 2014; Srinivasan 2008). An impeller, a major part of the pump, transfers energy to the fluid and the fluid flow is characterized by diffusion, vortices, strong swirl, separation, reverse flow and recirculation (Tuzson 2000). The centrifugal pump performance is dependent upon the impeller diameter, the width of the impeller, the number of blades $(Z)$ mounted on the impeller, blade profile and inlet and the exit blade-angles $(\beta)$ etc. (Srinivasan 2008; Bellary and Samad 2016). Several researchers investigated the effects of various geometric parameters on the performance of centrifugal pumps. Geometric parameters should be altered carefully so that the basic design of the pump cannot be disturbed (Srinivasan 2008; Gulich 2010). To do so, one has to change the shape of the impeller rather than changing the key dimensions. Proper design parameters and operating range selections are important to enhance the pump performance.

During the last few decades, the effects of geometric parameters on the pump performance have been extensively investigated. Kamimoto and Matsuoka (1956) investigated the internal flow mechanism experimentally and have shown $40 \%$ improvement in hydraulic efficiency of an impeller with $30^{\circ}$ EBA. Varley (1961) reported that a higher $\beta$ gives a higher head for a double suction centrifugal pump, but they skipped reporting the flow mechanism in detail. Aoki et al. (1987) and Ohta and Aoki (1996) have reported that higher $\beta$ improves the performance of the pump with water as working fluid (Varley 1961). Murakami et al. (1980) measured flow patterns in centrifugal pumps at both design and off-design conditions and concluded that the velocity and pressure distributions of seven-blade impeller coincide, whereas for three-blade impeller the deviation was large.

Fard and Boyaghchi (2007) and Li (2011) reported similar works results on the centrifugal pump. Fard et al. (2012) investigated the effect of $\beta$ for oil as working fluid, both experimentally and numerically, and showed that the increase of $\beta$ improves the performance. Shigemitsu et al.
(2011) investigated flow through a mini turbopump and the effects of $\beta$, and reported that the best efficiency point shifts towards higher values for higher $\beta$. Experiments on water and viscous oils show that the $Z$ influenced the performance of oil pumps and their effects decreased as fluid viscosity increased (Li 2011). Houlin et al. (2010) numerically investigated the flow characteristics of a centrifugal pump with different $Z$ and compared their results with those of the experiments. An increase in $Z$ leads to an increase of pressure fluctuations on the pressure side and on the whole diffuser vane surface (Feng et al. 2007).

The experimental and numerical analysis show that $Z$ affects the head generation (Rababa 2011; Bellary et al. 2016). Kim et al. (2014) performed design optimization of a centrifugal pump using CFD-based analysis and response surface method. The optimized design showed approximately $0.6 \%$ higher efficiency and $1.0 \mathrm{~m}$ higher head. Yan et al. (2017) redesigned a low efficiency and high vibration pump using CFD analysis. The redesigned pump showed about $3 \%$ higher efficiency than the baseline pump. Alemi et al. (2015) investigated volute geometry effects on the pump head, efficiency and radial force of a low-specific-speed pump. The authors concluded that the circular cross section volute casing with radial diffuser provides higher head and efficiency.

More often, industries transport fluids having high viscosities. Several researchers have reported the effect of viscosity on pump performance. Siddique et al. (2017) reported that the high viscosity skin-friction losses decreased with the increase of surface roughness. Bai et al. (2017) analyzed and compared the submersible pump head and efficiency to a different combination of number-of-blades of the impeller and diffuser vanes. Korkmaz et al. (2017) performed experiments on different blade angles and concluded that the impeller with less blade angle has superior performance as compared to that of large exit blade angle. The results revealed that the less number of impeller and diffuser vanes favored the rise in head and efficiency at the design point.

Although many researchers reported experimental and numerical investigations of the centrifugal pump with water as working fluid, there is a scarcity of deterministic literature on centrifugal pumps for crude oil transportation. In this study, the performance enhancement of a centrifugal pump and the effects of several design parameters have been 
investigated with detailed description for complex flow behavior, velocity, and pressure distributions. An attempt has been made to understand the combined effect of the blade numbers $(Z)$ and the exit blade angle $(\beta)$ for crude oil transportations.

\section{Experimental and Numerical Model}

\subsection{Pump Facility, Experimental Setup and Test Conditions}

The centrifugal pump used in this study to optimize the performance is shown in Fig. 1. The pump has un-vanned single volute casing with circular cross section. The pump has a rotational speed of $1340 \mathrm{rpm}(\mathrm{N})$ and a specific speed of $70(\mathrm{Ns})$. The total head is $5.05 \mathrm{~m}(\mathrm{H})$ at the design point which is having a mass flow rate of $\dot{\mathrm{m}}_{\text {des }}=2.171 \mathrm{~kg} / \mathrm{s}$. The design parameters and test conditions are presented in Table 1 . The experimental set-up was installed in the Wave Energy and Fluids Engineering Laboratory of the Department of Ocean Engineering- IIT Madras (Fig. 2). Two differential pressure gauges measured the pump suction and delivery pressure. A needle valve located between the pump outlet and flow meter regulated the flow and a flow meter measured the flow rate. A 3-phase DC-induction motor operated by a variable frequency drive, drove the pump at a constant speed $(\mathrm{N}=1340 \mathrm{rpm})$. The change in pressure at the suction and the delivery sides by adjusting flow control valves were recorded. A voltmeter and an ammeter gave the input power. The losses in the motor were considered to calculate the pump input power. The pump head was calculated by measuring pressures at the inlet $\left(P_{1}\right)$ and the outlet $\left(P_{2}\right)$, i.e.

$$
H=\left(\frac{P_{2}-P_{1}}{\rho g}\right)
$$

Including slip factor, the pump head is estimated by the following relation (Japikse $e t$ al. 1997);

$$
H_{\text {man }}=\sigma \frac{u^{2}}{g}\left(1-\frac{c_{m}}{u} \cot \beta\right)
$$

Where $\mathrm{u}$ is the peripheral velocity and $\mathrm{c}_{\mathrm{m}}$ is the meridional component of velocity at the exit due to slip. Wiesner (1967) related Z with slip factor as;

$\sigma=1-\frac{\sqrt{\sin \beta}}{Z^{0.7}}$

Hydraulic efficiency is given by;

$\eta_{h}=\frac{H_{\text {act }}}{H_{\text {theo }}}=\frac{H_{\text {theo }}-\Delta H}{H_{\text {theo }}}$

Relationship between overall efficiency and hydraulic efficiency is given by;

$\eta_{o v}=\eta_{\text {mech }} \times \eta_{v o l} \times \eta_{h}$

Following relationship was used to calculate the input power to the pump by measuring input voltage and current including motor losses;

$M_{\text {in }}=\sqrt{3} \times E I \cos \phi \times \eta_{\text {motor }}$

where, $E$ and $I$ are the applied voltage and current to the motor. The output power was determined by the formula;

$M_{\text {out }}=\rho \times g \times H_{\text {man }} \times Q$

(7)

Then, the pump efficiency was determined by the relationship;

$\eta_{\text {pump }}=\frac{M_{\text {out }}}{M_{\text {in }}}$

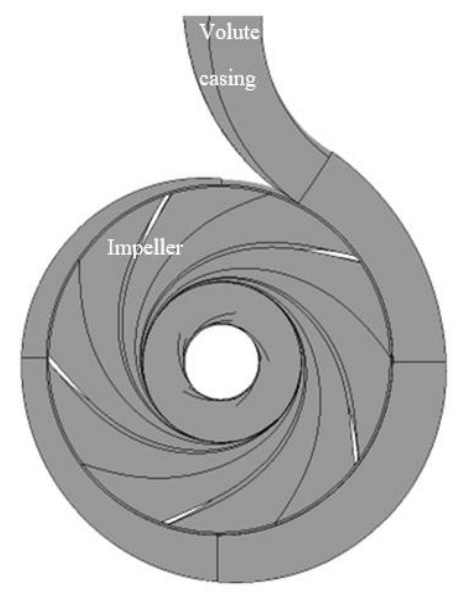

Figure 1. Schematic of centrifugal pump impeller and casing. 

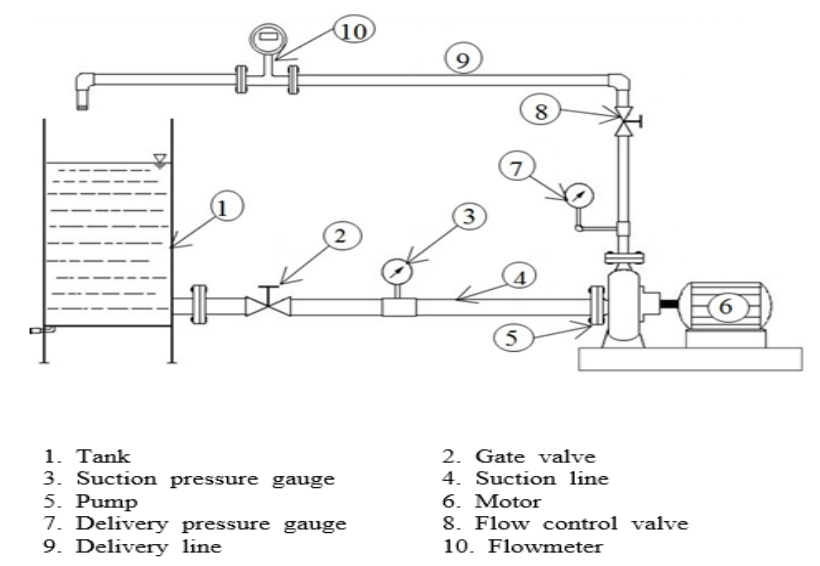
2. Gate valve
6. Motor
8. Flow control valve
8. Flow control

(a)

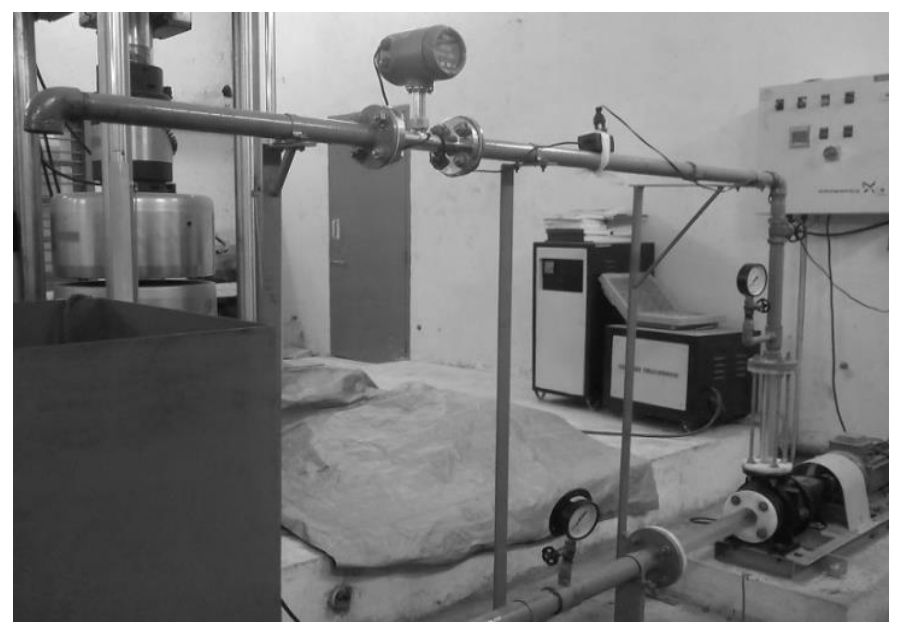

(b)

Figure 2. (a) Schematic of the experimental facility, and (b) experimental setup of the pump system.

Table 1. Specifications of the pump and, details of the experimental setup.

\begin{tabular}{ll}
\hline \multicolumn{1}{c}{ Parameter } & \multicolumn{1}{c}{ Dimension } \\
\hline Shaft diameter, $D_{\mathrm{s}}$ & $24 \mathrm{~mm}$ \\
Inlet diameter, $D_{1}$ & $63 \mathrm{~mm}$ \\
Inlet blade width, $b_{1}$ & $23 \mathrm{~mm}$ \\
Outlet blade width, $b_{2}$ & $10 \mathrm{~mm}$ \\
Inlet blade angle at shroud, $\beta_{\mathrm{shr}}$ & $11^{\mathrm{o}}$ \\
Inlet blade angle at hub, $\beta_{\mathrm{hub}}$ & $31^{\circ}$ \\
Outlet blade angle, $\beta$ & $36^{\circ}$ \\
Blade number, $Z$ & 5 \\
Blade thickness, $t$ & $3 \mathrm{~mm}$ \\
Outlet diameter, $D_{2}$ & $142 \mathrm{~mm}$ \\
Base circle diameter of volute & $147 \mathrm{~mm}$ \\
casing, $D_{3}$ & $15 \mathrm{~mm}$ \\
Volute width at base circle, $b_{3}$ & $50 \mathrm{~mm}$ \\
Suction pipe diameter, $D_{\text {suc }}$ & $32 \mathrm{~mm}$ \\
Delivery pipe diameter, $D_{\text {del }}$ & \\
\hline
\end{tabular}


The crude oil of the experiment was obtained from Oil and Natural Gas Corporation (ONGC), Karaikal, India. Its properties were extracted from the Gas Hydrate and Flow Assurance Laboratory of the Department of Ocean Engineering- IIT Madras.

\subsection{Numerical Model}

In the present study, Reynolds-Averaged Navier-Stokes (RANS) equations were solved for the incompressible and steady-state flow using a Computational Fluid Dynamics (CFD) solver and $k-\varepsilon$ turbulence closure model was used (ANSYS Solver Theory 2010). The impeller and casing geometries, having dimensions given in Table 1, were constructed in BladeGenv13 and CATIA-v5, respectively. These geometries were assembled in a design modeler. It was meshed with unstructured grids in ANSYS Turbogrid as shown in Fig. 3. Table 2 shows the number of nodes, elements, boundary conditions, and the convergence criteria.

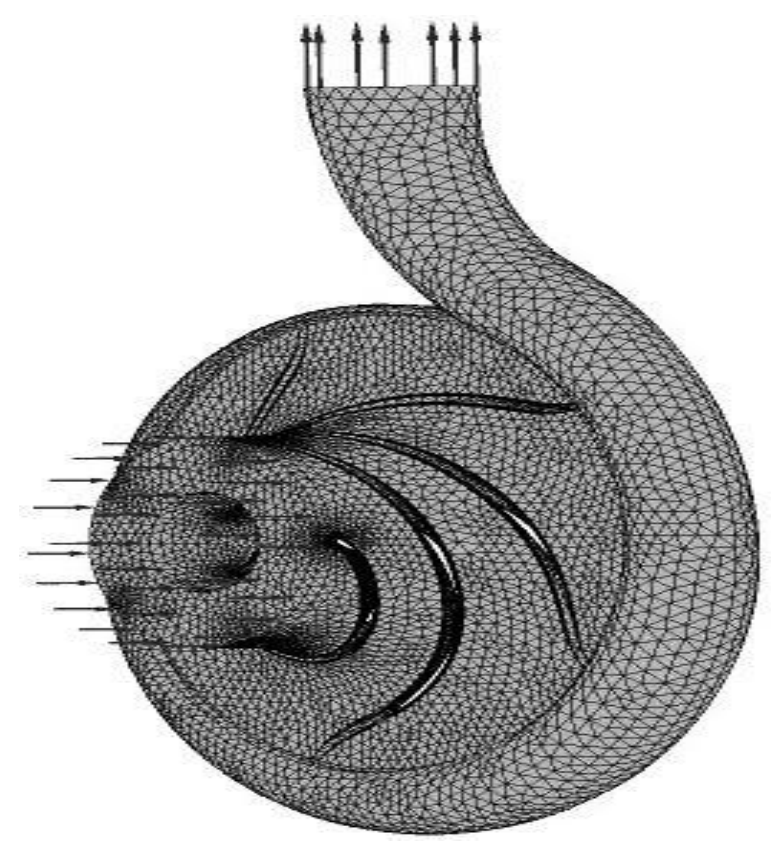

Figure 3. Computational domain with unstructured mesh.

Table 2. details of flow modeling and boundary conditions.

\begin{tabular}{ll}
\hline \multicolumn{1}{c}{ Parameter } & \multicolumn{1}{c}{ Dimension } \\
\hline Flow domain & $\begin{array}{l}\text { Impeller and Volute } \\
\text { casing }\end{array}$ \\
Interface & Frozen rotor \\
Mesh/Nature & Unstructured \\
Total nodes & 150000 \\
Total elements & 500000 \\
Fluid nature & Water and crude oil \\
Turbulence model & $k-\varepsilon$ \\
Inlet & Pressure \\
Outlet & Mass flow rate \\
Residual convergence & $1 \times 10^{-5}$ \\
value & \\
Time taken for single & $6 \mathrm{~h}$ \\
simulation & $1 \times 10^{-4} \mathrm{~kg} / \mathrm{s}$ \\
Mass imbalance & \\
\hline
\end{tabular}


The flow was simulated at various design and off-design points. Although the mesh was not resolved finely for boundary layer capturing, it provided reasonably accurate results for the overall pump performance characteristics. At the impeller leading and trailing edges, near the blade surface and in the volute casing, fine meshes were applied. A fine mesh on the blade surface captures flow behavior more accurately and helps achieving linear velocity distribution in the viscous sublayer. The RANS equations can be written in tensor form as;

$$
\frac{\partial U_{i}}{\partial x_{i}}=0
$$

$$
\rho U_{j} \frac{\partial U_{i}}{\partial x_{j}}=-\frac{\partial P}{\partial x_{i}}+\frac{\partial}{\partial x_{j}}\left[\left(\mu+\mu_{t}\right)\left(\frac{\partial^{2} U_{i}}{\partial x_{j} \partial x_{j}}\right)\right]
$$

Here, turbulent viscosity is modeled by the $k$ $\varepsilon$ model (turbulence model) as;

$\mu_{t}=C_{\mu} \rho \frac{k^{2}}{\varepsilon}$

The equations for turbulent kinetic energy and dissipation rate can be written as;

$$
\begin{aligned}
& \rho U_{j} \frac{\partial k}{\partial x_{j}}=\frac{\partial}{\partial x_{j}}\left[\left(\mu+\frac{\mu_{t}}{\sigma_{k}}\right) \frac{\partial k}{\partial x_{j}}\right]+P_{k}-\rho \varepsilon \\
& \rho U_{j} \frac{\partial \varepsilon}{\partial x_{j}}=\frac{\partial}{\partial x_{j}}\left[\left(\mu+\frac{\mu_{t}}{\sigma_{\varepsilon}}\right) \frac{\partial \varepsilon}{\partial x_{j}}\right]+\frac{\varepsilon}{k}\left(C_{\varepsilon 1} P_{k}-C_{\varepsilon 2} \rho \varepsilon\right)
\end{aligned}
$$

Here,

$$
P_{k}=\mu_{t}\left(\frac{\partial U_{i}}{\partial x_{j}}+\frac{\partial U_{j}}{\partial x_{i}}\right) \frac{\partial U_{i}}{\partial x_{j}}
$$

The values of the closing constants are $C_{\mu}=0.09, C_{\varepsilon 1}=1.44, C_{\varepsilon 2}=1.92, \sigma_{k}=1.0$ and $\sigma_{\varepsilon}=1.3$.

The $k-\varepsilon$ turbulence closure model uses the scalable wall-function to improve the robustness and accuracy. The scalable wall function allows solution on arbitrarily fine near wall grids, which is a significant improvement over standard wall functions (ANSYS Solver Theory 2010; Husain et al. 2013). It allows consistent mesh refinement and remains accurate for a fairly wide range of $\mathrm{y}^{+}$values. The solver employs a Multigrid approach which solves the hydrodynamic equations for velocity and pressure $(\mathrm{u}, \mathrm{v}, \mathrm{w}, \mathrm{p})$ as a single system and uses a fully implicit discretization of the equations for a given time step. Also, it uses a MultiGrid accelerated Incomplete Lower Upper factorization technique for solving the discrete system of linearized equations.

\section{Results and Discussion}

The grid dependency of the numerical scheme was checked before carrying out CFD analysis. The reference parameter for the grid analysis was the pump head at the design conditions. The pump head showed asymptotic behavior with an increase of node numbers as shown in Fig. 4. Once the number of nodes reached a value of $\sim 150,000$, it affected the head generation insignificantly. The convergence criterion for the iterative solutions was a maximum residual of $10^{-5}$. Several turbulence closure models are available and their suitability depends upon CFD applications. Bradshaw (1966) reported that the turbulence selection model depends upon: a) the physical nature of the problem, b) the quality of attained results and c) the computing power. In spite of this, the traditional RANS analysis with $k-\varepsilon$ or $k-\omega$ is widely used and satisfactory results are obtained. Two turbulence closure models, namely $k-\varepsilon$ and SST, were compared for their performances at design point under similar conditions in this problem. Experimental results produced $5.05 \mathrm{~m}$ head at the best efficiency point. The head produced by using $k-\varepsilon$ and SST turbulence models are 5.42 and $5.95 \mathrm{~m}$, respectively (Fig. 5). The $k-\varepsilon$ with scalable wall function produced the least error $(6.8 \%)$ and was chosen for further analysis.

The computations were carried out at several flow rates ie. at design and off-design conditions of water and crude oil, gave reasonably accurate results as compared to the experimental ones. At the design and off-design points, the calculated heads were overestimated by $6.8 \%$ and $4.8 \%$ as compared to those of the experimental results, respectively. Qualitatively, the present results satisfy the accuracy level as reported in the literature (Gupta et al. 2011; Patel and Ramakrishnan 2006), and the discrepancies reported by (Gulich 2010). Both experiments and simulations were performed with several flow rates at $1340 \mathrm{rpm}$. Oil industries handle different fluids with varying viscosities. In the present investigation, two fluids, namely, water and crude oil, which have 


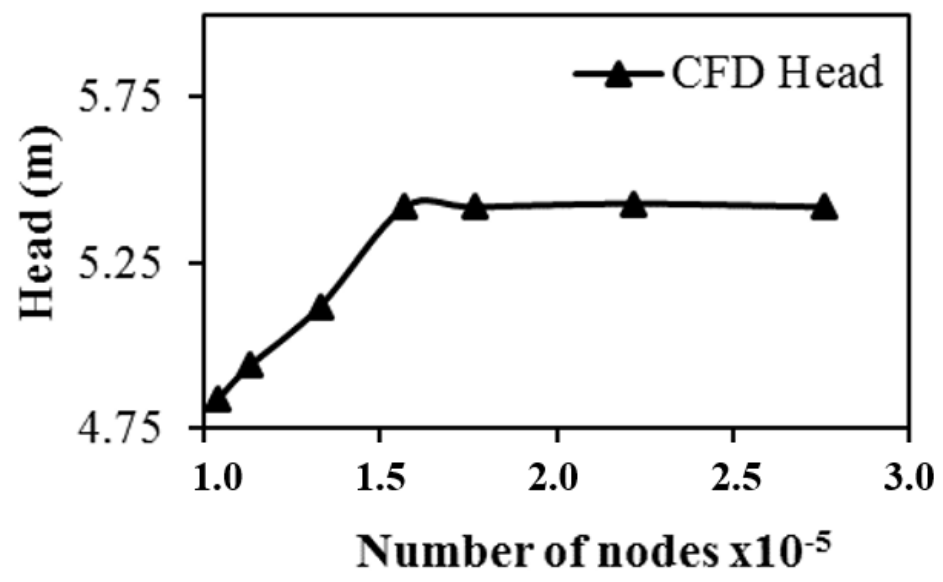

Figure 4. Grid test typically for RANS analysis using k- $\varepsilon$ turbulence model.

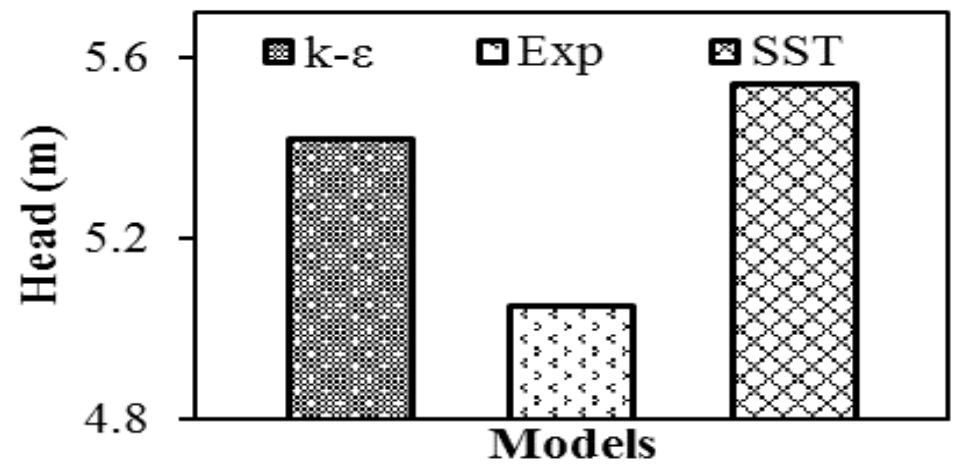

Figure 5. Comparison of results using turbulence models with experimental data.

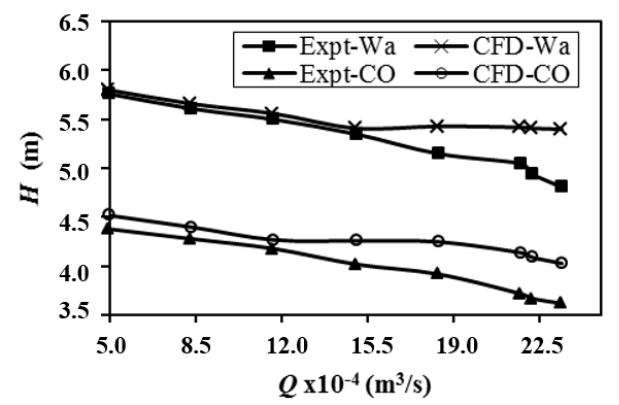

(a)

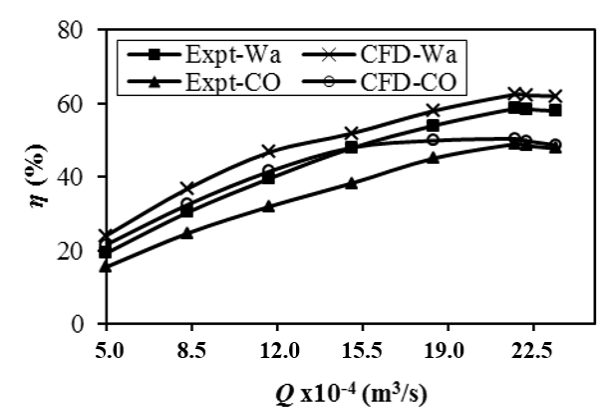

(b)

Figure 6. Comparison of (a) pump head and (b) efficiency, against flow rate obtained from CFD and experiments for water (Wa) and crude oil (CO) as working fluids. 
the crude oil then the water. The decrease in the efficiency and head was caused by the high viscosity, which gives high disc friction losses over the impeller shroud and hub as obvious from Eq. (4). These results in Fig. 6 are in good agreement with the available literature of Gulich (2010) and Li (2000) which represents variation in efficiency $(\eta)$ and head with flow rate.

The pump shows the maximum efficiency $(\eta)$ at the design-point, at which hydraulic losses, profile losses, and the secondary losses are minimum. On the contrary, at all other points (off-design points) shock losses and secondary losses increase, resulting into higher hydraulic losses and decrease in hydraulic efficiency, which consequently results in a decrease in overall efficiency. At the low flow rates, reverse flow and inlet recirculation are prominent and they increase with a further reduction in flow rate. The results for water as working fluid showed higher values of head and efficiency than that of crude oil (Fig. 6).

The flow characteristics of crude oil as a fluid medium were investigated in detail through velocity, vorticity and pressure distribution on several $x-y$ planes. Fig. 7 shows vorticity distribution on $x-y$ planes in the axial direction (z-direction) in the middle of the impeller at $\mathrm{z}=$ $30 \mathrm{~mm}$. In general, higher vorticity distributions are present near the inner and outer rings of the impeller, though smaller $Z$ exhibited higher vorticity towards outer rings. With the increase of $Z$ higher vorticity regions were developed near the inner ring due to the increasing boundary layer effects. An increase in $\beta$ reduced the vorticity distribution near the inner ring as shown in Fig. 8.

Higher fluid velocity regions appeared towards the impeller outer ring because of the higher radial distance as shown in Fig. 9. The velocity increases suddenly as the fluid moves into the volute casing. While moving into the volute casing, the kinetic energy changed into pressure energy, which consequently increased static pressure of the fluid as shown in Fig. 10.

Figure 11 represents the CFD characteristics of the pump head and efficiency with the change of $Z$ and $\beta$ at the designed flow rate. It is clearly reflected that the pump head decreased with increasing volume flow rate due to a decrease in liquid pressure drop. In addition, the pump head increased with increasing $Z$. This can be explained by the fact that when the volume flow rate was kept constant, an increase in $\mathrm{Z}$ leads to decrease in liquid pressure drop, which consequently increases the pump head. Also, impeller outlet velocity was increased and the velocity distribution became smoother with an increase in $Z$ and converted into highpressure energy through impeller-volute. The effective area of interest at impeller-volute intersection became more obvious which improved the discharge capability of the pump and consequently higher head was generated. With the increase in $Z$, the flow within the impeller becomes more uniform and reduces the hydraulic losses due to mixing fluid particles. The uniform flow suppresses jet growth and wake phenomena. In addition, smooth pressure and velocity distribution were observed near the impeller exit and volute inlet as shown in Fig. 9 and 10. Hence, the pump efficiency was increased.

The impeller with large $\beta$ resulted in an increase of head generation. It is due to increase in absolute flow velocity at exit $\left(c_{2}\right)$ and corresponding peripheral velocity $\left(c_{\mathrm{u} 2}\right)$ ie. dynamic part of the head. Eq. (2) clearly, indicates the impact of the two design parameters $c_{\mathrm{m}} / \mathrm{u}_{2}$ and $\beta_{2}$ on the head. An increase in $\beta_{2}$ reduced the $c_{\mathrm{m}} / \mathrm{u}_{2}$ and as a result, the manometric head increased. Additionally, the influence of slip factor has to be considered. Slip factor value decreases with an increase in exit blade angle and partly curtails the effect of $\beta$ (Bacharoudis et al. 2008). As a total effect, any increase in $\beta$ results in an increase of head generation. The change in slip factor value affects the shape of the $H-Q$ curve and more significantly for $\beta$ greater than $25^{\circ}$ (Bacharoudis et al. 2008). It is evident from Eq. (3) that the higher $Z$ facilitates an increase in slip factor and consequently head augmentation. The hydraulic losses at design point differ by a small amount from off-design conditions; a measure of hydraulic efficiency is directly linked with hydraulic losses. The overall efficiency decreases due to a decrease of hydraulic efficiency. Moreover, the pump brake horsepower increases due to the augmentation in $\beta$ and $Z$. This is due to the increase in the requested shaft torque associated with the increased $\beta$ (Djerroud et al. 2011).

Table 3. Properties of water and crude oil.

\begin{tabular}{ccc}
\hline Fluid & $\begin{array}{c}\text { Viscosity } \\
{\left[\mathrm{N.s} / \mathrm{m}^{2}\right]}\end{array}$ & $\begin{array}{c}\text { Density } \\
{\left[\mathrm{kg} / \mathrm{m}^{3}\right]}\end{array}$ \\
\hline Water & 0.001 & 997 \\
Crude-oil & 0.0025 & 823 \\
\hline
\end{tabular}




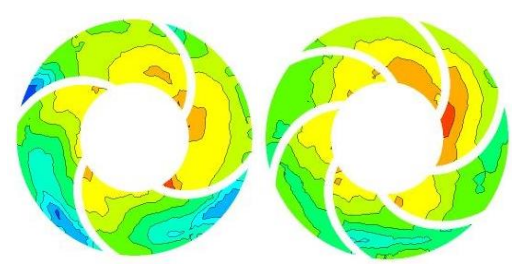

(a)

(b)

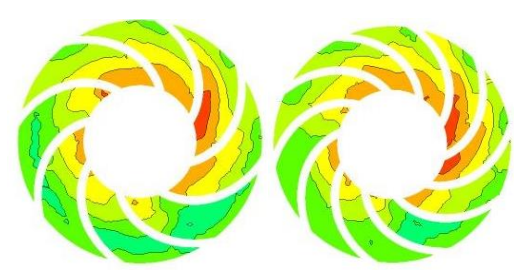

(c)

(d)

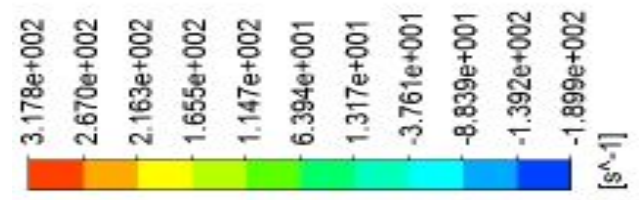

Figure 7. Vorticity distribution in $z$-direction on $x-y$ plane at $z=30 \mathrm{~mm}$ from inlet for exit blade angle $\beta=50^{\circ}$ and number of blades (a) $Z=4$, (b) $Z=6$, (c) $Z=8$ and (d) $Z=10$ for pumping crude oil.

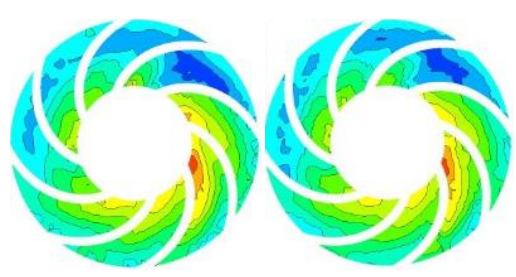

(a)

(b)

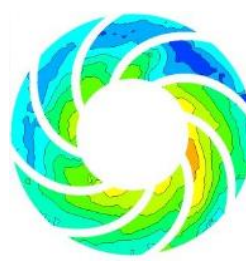

(c)

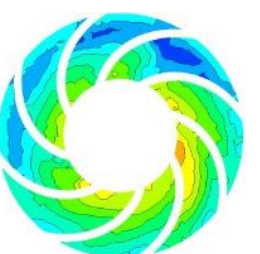

(d)

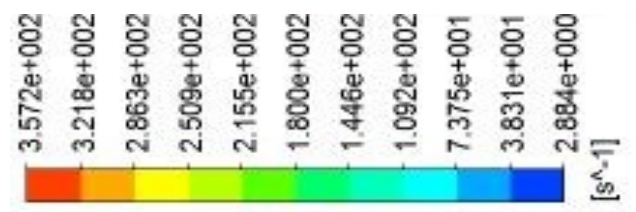

Fig.ure 8. Vorticity distribution in $z$-direction on $x-y$ plane at $z=30 \mathrm{~mm}$ from inlet for number of blades $Z=8$ and exit blade angle (a) $\beta=20^{\circ}$, (b) $\beta=30^{\circ}$, (c) $\beta=40^{\circ}$ and (d) $\beta=50^{\circ}$ for pumping crude oil. 


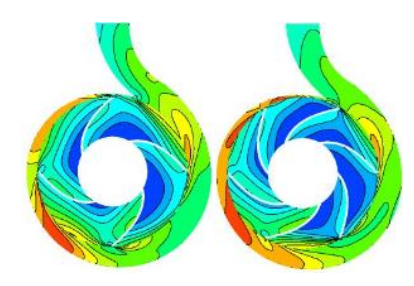

(a)

(b)

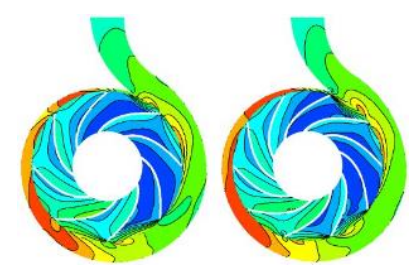

(c)

(d)

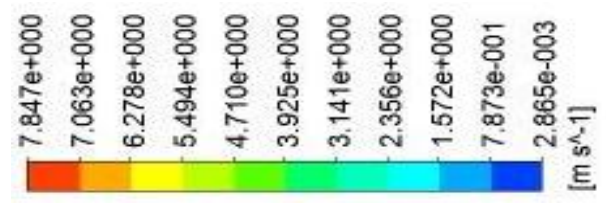

Figure 9. Velocity distribution in $z$-direction on $x-y$ plane at $z=50 \mathrm{~mm}$ from inlet for exit blade angle $\beta=50^{\circ}$ and number of blades (a) $Z=4$, (b) $Z=6$, (c) $Z=8$ and (d) $Z=10$ for pumping crude oil.

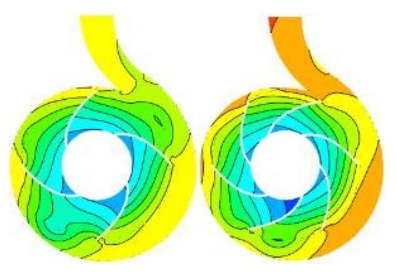

(a) (b)

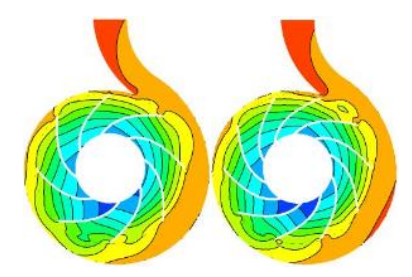

(c) (d)

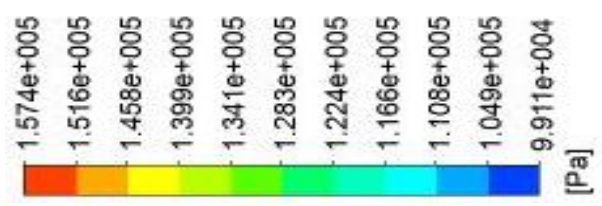

Figure 10. Pressure distribution on $x-y$ plane at $z=50 \mathrm{~mm}$ from inlet for exit blade angle $\beta=50^{\circ}$ and number of blades (a) $Z=4$, (b) $Z=6$, (c) $Z=8$ and (d) $Z=10$ for pumping crude oil. 
The effect of $\beta$ on the pump performance used for crude oil was explored through CFD for the change of flow rate as shown in Fig. 12. Once the $Z$ (which is 8 ) was frozen, the $\beta$ was altered from $30^{\circ}-50^{\circ}$. Similar trends were observed in which an increase in $\beta$ has augmented the head generation significantly. Any increase in $\beta$ always leads to broader outlet cross sections (Li 2011; Djerroud et al. 2011) which results in a fall of fluid pressure loss and consequently the head is augmented. It is observed that any increase in $\beta$ has a substantial influence on the hydraulic efficiency, which increased continuously until the design point is reached. At the off-design point, an increase in $\beta$ does not increase much of the hydraulic efficiency, instead, decreases due to several losses (Srinivasan 2008).

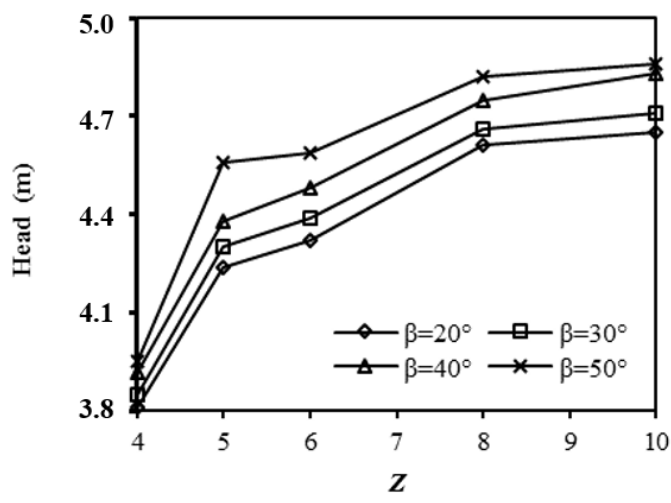

(a)

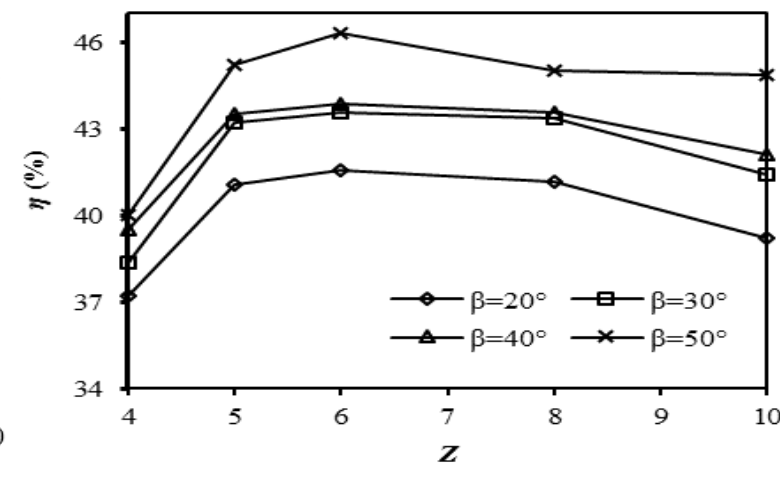

(b)

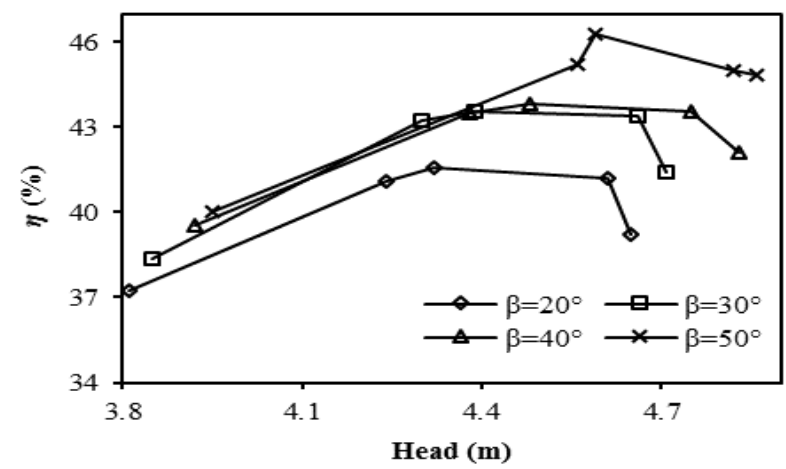

(c)

Figure 11. CFD results on the effects of number of blades and exit blade angle on the pump performance for crude oil at design point flow rate: (a) Head vs z, (b) Efficiency vs z and (c) Efficiency vs head.

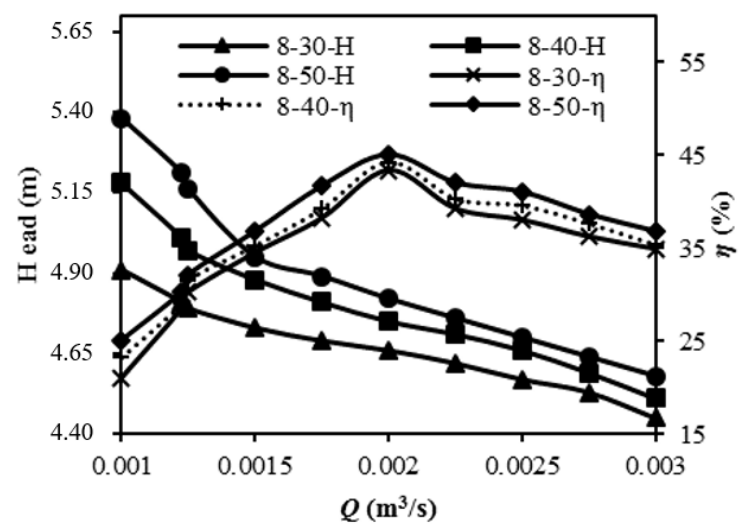

Figure 12. CFD characteristic of head and efficiency with a change of flow rate for crude oil. 


\section{Conclusion}

The centrifugal pump performance investigation and optimization has been carried out for water and crude oil as working fluids at the design and off-design flow rates by experimental and numerical analysis techniques. Several combinations of exit bladeangles $(\beta)$ and number of blades $(Z)$ were investigated for the parametric optimization. On the basis of the present study, the following conclusions can be derived;

- The increase in $Z$ has a significant influence on the head and efficiency of the pump for both water and crude oil. The distribution of vortices was more uniform with less magnitude near the impeller inlet and its distribution increased randomly with high magnitude near impeller exit for high $Z$. With less $Z$ the vortices became prominent and more obvious near the impeller outlet.

- Due to non-mixing of fluid particles at higher $Z$, jet wake phenomenon is absent and more streamlined flow was achieved which has contributed in head augmentation.

- The $\beta$ has a considerable influence on the head and pump efficiency for different viscosity liquids. An increase in $\beta$ increases the pump efficiency until it reached a maximum rate at the design point. At off-design points, an increase in $\beta$ decreases its efficiency because of increased hydraulic losses. Higher viscosity liquid or crude oil has a lower head generation at the same $\beta$ because of disc friction, shock and secondary losses.

- Combined effect of increase in $\beta$ and $Z$ increases head generation with negligible increase in hydraulic efficiency.

\section{Conflict of Interest}

The authors declare no conflicts of interest.

\section{Funding}

The authors would like to acknowledge Indian Institute of Technology Madras for the NFSC grant (Grant Code: OEC/1011/529/NFSC/ABDU).

\section{Acknowledgment}

The authors acknowledge the support of manager of Oil and Natural Gas Corporation
(ONGC)-Karaikal for conducting this research the facilities received from Gas Hydrate and Flow Assurance Lab in the Department of Ocean Egineering- IIT Madras to determine the properties of crude oil. Also, the authors acknowledge the support of Sultan Qaboos University for conducting this research.

\section{References}

Alemi H, Nourbakhsh SA, Raisee M, Najafi AF (2015), Effects of volute curvature on performance of a low specific-speed centrifugal pump at design and off-design conditions. Journal of Turbomachinery 137:041009-1-10.

ANSYS13.0. (2010) ANSYS Inc.

Aoki K, Ohta H, and Nakayama Y (1987), Study on Centrifugal Pump for High Viscosity Liquids (The 1st Report, Effect of Impeller Output Angle and Number of Blades on the Pump Performance of Closed Type Impellers). Proceedings of the School of Engineering, Tokai university 27(2):151-158.

Bacharoudis EC, Filios AE, Mentzos MD, Margaris DP (2008), Parametric study of a centrifugal pump impeller by varying the outlet blade angle. The Open Mechanical Engineering Journal 2:75-83.

Bai Y, Kong F, Xia B, Liu Y (2017), Effect of blade number matching of impeller and diffuser in high-speed rescue pump. Advances in Mechanical Engineering 9(5):1-12.

Bellary SAI, Samad A (2014), Numerical analysis of centrifugal impeller for different viscous liquids. International Journal of Fluid Machinery and System 8(1):36-45.

Bellary SAI, Samad A (2016), Pumping Crude Oil by Centrifugal Impeller Having Different Blade Angles and Surface Roughness. Journal of Petroleum and Exploration and Production Technology 6(1):117-127.

Bellary SAI, Adhav R, Samad A, Chon BH, Kenyery F (2016), Applications of Computational Fluid Dynamics and Surrogate-Coupled Evolutionary Computing to Enhance Centrifugal Pump Performance. Engineering Applications of Computational Fluid Mechanics 10(1):172-182.

Bradshaw P (1996), Turbulence modeling with application to turbomachinery. Progress in Aerospace Sciences 32(6): 575-624.

Djerroud M, Ngoma GD, Ghie W (2011), Numerical identification of key design parameters enhancing the centrifugal pump 
performance: impeller, impeller-volute, and impeller-diffuser. ISRN Mechanical Engineering, Article ID 794341, 16 pages, doi:10.5402/2011/794341.

Fard MHS, Boyaghchi FA (2007), Studies on the influence of various blade outlet angles in a centrifugal pump when handling viscous fluids, American Journal of Applied Sciences 4(9):718-724.

Fard MHS, Tahani M, Ehghaghi MB, Fallahian MA, Beglari M (2012), Numerical study of the effects of some geometric characteristics of a centrifugal pump impeller that pumps a viscous fluid. Computers and Fluids 60:61-70.

Feng J, Benra FK, Dohmen HJ (2007), Numerical investigation on pressure fluctuations for different configurations of vaned diffuser pumps. International Journal of Rotating Machinery, Article ID 34752, 10pages. doi:10.1155/2007/34752.

Gulich JF (2010), Centrifugal Pumps, 2nd Edition, Springer Publications, Berlin.

Gupta M, Kumar S, Kumar A (2011), Numerical study of pressure and velocity distribution analysis of centrifugal pump. International Journal of Thermal Technologies 1(1):117-121.

Houlin L, Yong W, Shouqi Y, Minggao T, Kai W (2010), Effects of blade number on characteristics of centrifugal pumps. Chinese Journal of Mechanical Engineering 23: 1-6.

Husain A, Kim SM, Kim JH, Kim KY (2013), Thermal performance analysis and optimization of microjet cooling of highpower light-emitting diodes. Journal of Thermophysics and Heat Transfer 27(2): 235245.

Japikse D, Marscher WD, Furst RB (1997), Centrifugal Pump Design and Performance Concepts ETI, Inc., Vermont, USA.

Kamimoto G, Matsuoka Y (1956), On the flow in the impeller of centrifugal type hydraulic machinery (The 2nd Report). Transactions of the JSME, Series 3, 22(113): 5.

Kim J-H, Lee H-C, Kim J-H, Kim S, Yoon J-Y, Choi Y-S (2015), Design techniques to improve the performance of a centrifugal pump using CFD. Journal of Mechanical Science and Technology 29(1): 215-225.

Korkmaz, E, Golcu, M, and Kurbanoglu, C (2017), Effects of blade discharge angle, blade number and splitter blade length on deep well pump performance. Journal of Applied Fluid Mechanics, 10(2): 529-540.

Li WG (2000), Effects of viscosity on the performance of a centrifugal oil pump and the flow pattern in the impeller. International Journal of Heat and Fluid Flow 21(2): 271-275.

Li WG (2002), The influence of number of blades on the performance of centrifugal oil pumps. World Pumps 427: 32-35.

Li WG (2011), Blade exit angle effects on performance of a standard industrial centrifugal oil pump. Journal of Applied Fluid Mechanics 4(2): 105-119.

Murakami M, Kikuyama K, Asakura E (1980), Velocity and pressure distributions in the impeller passages of centrifugal pump. ASME J. of Fluids Eng. 102: 420-426.

Ohta H, Aoki K (1996), Effect of impeller angle on performance and internal flow of centrifugal pump for high viscosity liquids. Proceedings of the School of Engineering, Tokai University 36(1): 159-168.

Patel K, and Ramakrishnan N (2006), CFD analysis of mixed flow pump. International ANSYS Conference Proceedings.

Rababa KS (2011), The effect of blades number and shape on the operating characteristics of groundwater centrifugal pumps. European Journal of Scientific Research 52(2): 243-251.

Siddique MH, Samad A, Husain A (2017), Combined effects of viscosity and surface roughness on electric submersible pump performance. Journal of Power and Energy $0(0): 1-14$.

Srinivasan KM (2008), Rotodynamic Pumps. New Age International (P) Ltd., New Delhi.

Shigemitsu T, Fukutomi J, Nasada R, Kaji K (2011), The effect of blade outlet angle on performance and internal flow condition of mini turbo-pump. Journal of Thermal Science 20(1): 32-38.

Tuzson (2000), Centrifugal Pump Design, John Wiley and Sons, Inc., $1^{\text {st }}$ Edition, New York. 5-59.

Varley FA (1961), Effects of impeller design and surface roughness on the performance of centrifugal pumps. Proc. Instn. Mech. Engrs, 175(21): 955-969.

Wiesner FJ (1967), A review of slip factors for centrifugal impellers. ASME J. Eng. Power 89: 558-566.

Yan $\mathrm{P}$, Chu N, Wu D, Cao L, Yang S, Wu P (2017), Computational fluid dynamicsbased pump redesign to improve efficiency and decrease unsteady radial forces. Journal of Fluids Engineering 139: 011101-111. 